Copyright $\odot 2018$ The Author(s). Published by BCS, The Chartered Institute for IT under Creative Commons license http://creativecommons.org/ licenses/by/4.0/

\section{Digital disparities, complexity and patient safety: in this issue}

\author{
Simon de Lusignan \\ Editor in Chief, Journal of Innovation in Health Informatics \\ Professor of Primary Care \& Clinical Informatics, University of Surrey, Guildford, UK
}

\section{INTRODUCTION AND EDITOR'S CHOICE}

In this issue, we publish articles about how digital health and the skills needed to use it may increase disparities. Unsurprisingly, if you change health services from a system where the phone or a visit in person is the only way to interact with it to one with a complex set of different online tools there will inevitably be disparities, particularly among those who find it most difficult to adapt. In research published in this issue, age, income and educational levels are important predictors of lower uptake. We also describe the complexity of healthcare; the importance of records that support holistic care; and of providing actionable informatics to improve patient safety. The Editor's choice article in this issue is the paper by Williams et al.., ${ }^{1}$ on the use of a dashboard to improve prescribing safety.

\section{MORE POINTERS TOWARDS DIGITAL DISPARITIES}

We open this edition with an interesting paper about what predicts Internet use in older adults. ${ }^{2}$ This is critically important for health systems as they move to implement digital health strategies. They need to understand the scale of this problem. A paper by Emani et al., predicting who adopts a patient portal identified age and income as determinants of use. Additionally, the group of patients who expected benefits also used it more. ${ }^{3}$ This is also reinforced in other findings that online access to clinical records and other services that require Internet skills may increase disparities. ${ }^{4}$

\section{COMPLEXITY}

There are growing numbers of people with comorbidity, all of which have their own guidance; particularly for older people, we need to practice less disruptive medicine. ${ }^{5}$ A paper by Litchfield et al., ${ }^{6}$ looks to steer us through the dilemma created by multiple potentially conflicting guidelines and sets out how we might address these conflicts. A further area of complexity is that of interoperability. Interoperability has long been a 'Holy grail' of informatics, and Oyeyemi and $\mathrm{Scott}^{7}$ draw out its complexity.

\section{ENGEL'S BIOPSYCHOSOCIAL MODEL}

Engel's biopsychosocial model of disease set out in 1977 challenged biomedicine. ${ }^{8}$ Engel stated biomedicine 'leaves no room within its framework for the social, psychological and behavioural dimensions of illness. A biopsychosocial model is proposed that provides a blueprint for research, a framework for teaching and a design for action in the real world of healthcare'. Computerised medical record (CMR) 
systems are orientated towards the needs of biomedicine and Woodson ${ }^{9}$ describes how they struggle to meet the needs of behavioural health clinicians. It is possible that we need other tools to share information across teams and we publish a research letter from Sarkisian and Kagel ${ }^{10}$ explaining how they have used 'Slack' for collaborative medical work.

\section{THE PATIENT AS THE UNIT OF IMPLEMENTATION}

The patient rather than the organisation may be the best way of rolling out a new system. Gunja that provides a case study of an electronic prescribing system. The mantra was 'one patient one chart'!11 If only we could also take that phrase more widely into 'one patient one computerised medical record'!

\section{REFERENCES}

1. Williams R, Keers R, Gude WT, Jeffries M, Davies C, Brown B, et al. SMASH! The Salford medication safety dashboard. Journal of Innovation in Health Informatics 2018;25(3):183-93.

2. Arief $M$, Rissanen $S$ and Saranto $K$. Influence of previous work experience and education on Internet use of people in their 60s and 70s. Journal of Innovation in Health Informatics 2018;25(3):132-41.

3. Emani S, Peters E, Desai S, Karson AS, Lipsitz SR, LaRocca R, et al. Perceptions of adopters versus non-adopters of a patient portal: an application of diffusion of innovation theory. Journal of Innovation in Health Informatics 2018;25(3):149-57.

4. Mold F and de Lusignan S. Patients' online access to their primary care electronic health records and linked online services: implications for research and practice. Journal of Personalized Medicine 2015;5(4):452-69. doi: 10.3390/jpm5040452

5. Schattner $P$, Barker $F$ and de Lusignan S. Minimally disruptive medicine is needed for patients with multimorbidity: time to develop computerised medical record systems to meet this requirement. Journal of Innovation in Health Informatics 2015;22(1):250-4. doi: 10.14236/jhi.v22i1.136

6. Litchfield I, Turner A, Backman R, Filho JBF, Weber $P$ and Lee $M$. Automated conflict resolution between multiple clinical pathways: a technology report. Journal of Innovation in Health Informatics 2018;25(3):142-8.

7. Oyeyemi A and Scott P. Interoperability in health and social care: organizational issues are the biggest challenge. Journal of Innovation in Health Informatics 2018;25(3):196-8.

\section{MOBILE HEALTH TO SCREEN FOR CARDIOVASCULAR DISEASE}

In a month when Public Health England has launched its online tool to predict your heart age, ${ }^{12}$ we publish an article by Mannik et al., ${ }^{13}$ about how community health workers in rural Kenya have used a mobile app to screen for cardiovascular disease and risk.

\section{DASHBOARD TO IMPROVE QUALITY AND PATIENT SAFETY}

Williams et al. ${ }^{1}$ describe the development of a dashboard to improve patient safety, its focus is medication safety. The development of dashboards to improve quality is one I have an interest ${ }^{14}$ in and is the Editor's choice paper of this edition.

8. Engel GL. The need for a new medical model: a challenge for biomedicine. Science 1977;196(4286):129-36.

9. Woodson TT, Gunn R, Clark KD, Balasubramanian BA, Jetelina $\mathrm{KK}$, Muller $\mathrm{B}$, et al. Designing health information technology tools for behavioural health clinicians integrated within US-based primary care teams. Journal of Innovation in Health Informatics 2018;25(3):158-68.

10. Sarkisian SA and Kagel A. The use of slack for medical residency development and recruiting. Journal of Innovation in Health Informatics 2018;25(3):194-5.

11. Gunja N, Dunlop I, Vaghasiya M, Kuan K and Poon S. Patientcentric implementation of an electronic medication management system at a tertiary hospital in Western Sydney. Journal of Innovation in Health Informatics 2018;25(3):169-75.

12. How your heart age is key to heart attack or stroke risk. BBC News. Available from: https://www.bbc.com/news/ health-45395576. Accessed 4 September 2018.

13. Mannik JR, Figol A, Churchill V, Aw J, Francis S, Karino E, et al. Community-based screening for cardiovascular risk using a novel mHealth tool in rural Kenya. Journal of Innovation in Health Informatics 2018;25(3):176-82.

14. Pathirannehelage S, Kumarapeli P, Byford R, Yonova I, Ferreira $\mathrm{F}$ and de Lusignan $\mathrm{S}$. Uptake of a dashboard designed to give realtime feedback to a sentinel network about key data required for influenza vaccine effectiveness studies. Studies in Health Technology and Informatics 2018;247:161-5. 